\title{
Design and Development of Thermal Transmittance Tester for Textile Fabrics
}

\author{
Prakash C*, Bharathi S, Harini R, Raji P and Ummehani Aliasgar Bhagat \\ Department of Fashion Technology, Sona College of Technology, India
}

Submission: September 19, 2017; Published: January 05, 2018

*Corresponding author: Prakash C, Department of Fashion Technology, Sona College of Technology, Salem - 636005, Tamilnadu, India, Email: dearcprakash@gmail.com

\begin{abstract}
When a person touches a garment, heat flow occurs between the human body and the fabric, with the resulting warm-cool feeling as the first sensation. This transient and dynamic thermal-contact feeling should be carefully investigated, since it strongly affects people's first impressions and subsequent choices when buying garments. In this project, we have devised an instrument to find out the heat transmission properties of various fabrics, with varying weight and thickness of the fabric. The fabrics were tested in a natural as well as forced convective mode with air velocity of $1 \mathrm{~m} / \mathrm{s}$ flowing parallel over the fabric surface. It was observed that the thermal resistance of the fabric in forced convection is less than that in the natural convective mode. The instrument works on the principle of heat conduction, convection and radiation using the air blowing technique. Heat is passed in the form of hot air towards the glass plate which is then transmitted to the fabric placed on it and the temperature difference is noted. The value obtained is employed in the various formulae of heat transmission properties and thus thermal transmittance value is obtained. It is observed that the thermal properties vary with the change in the weight and thickness of the fabrics.
\end{abstract}

\section{Introduction}

Fabric thermal properties have been of great interest and importance for textile researchers, since they are among the major characteristics that determine wearing comfort. Traditionally, most measurements of fabric thermal properties were conducted in a state of equilibrium, analyzing such easily measured properties as thermal conductivity and resistance. However, these steady-state methods cannot explain the heatrelated subjective sensations that determine human comfort, because this approach does not reflect the real wearing situation, since the human body interacts with clothing [1-6]. The sudden mechanical contact of textile fabric with human skin causes a feeling of warmth or coolness due to the heat flow from the human body to the fabric that is at a lower temperature than the skin surface. The main aim of the research is to device an instrument that measures the fabric thermal properties in wearing situation and thus determines the values of thermal conductivity, resistance and transmittance of various fabrics. Thus in today's world where novel varieties of fabrics are being found the instrument helps in determining the wear ability of the fabrics based on the thermal properties and if these fabrics are appropriate for human clothing [7-9].

\section{Principle of operation}

\section{Thermal transmittance tester}

This is a tester to evaluate the warmth retaining efficiency of textile cloth. The instrument works on the principle of "heat conduction, convection and radiation using the air blowing technique". Heat is passed in the form of hot air towards the glass plate which is then transmitted to the fabric placed on it and the temperature difference is noted. The device consists of parts like Power supply, Testing chamber, Temperature Sensor/ Thermistor, Micro controller and LCD Interface/Digital display.

\section{Working}

The instrument is first switched on. The temperature is then calibrated to the room temperature $\left(29^{\circ} \mathrm{C}\right)$ in both the chambers. The fabric is cut according to the template ( 5 "x 5 ") and fixed over the glass plate, which is then inserted in the space between the two chambers. The test temperature $\mathrm{T} 1$ is then set using the setting knob. The changes in the temperature can be viewed on the LCD (Table 1-2). The heat is supplied by a horizontal air blower which blows in hot air generating the necessary amount of heat to be passed to the fabric through the glass plate. The glass plate is a good conductor of heat and thus helps conduct better transmission of heat through the fabric. These temperature changes are obtained by the temperature noting component called the Thermistor. There is a thermistor each in the two chambers which sense the temperatures and displays it on the LCD screen (Figure 1). The power is supplied and the temperatures are noted down until there are no changes in the temperature. Heat is passed through the fabric for at least one hour and the temperatures of $\mathrm{T} 2$ at the varying temperatures of $\mathrm{T} 1$ are noted down. The same procedure is repeated for various 
fabrics at various temperatures. Thus the difference in the temperature (T1-T2) is obtained from the instrument [10-14]. The following table gives various data's of the test samples for which the testing were carried out. All the samples are of the size 5"x5" (Table 3-4).

Table $1: 100 \%$ cotton woven fabrics (plain weave).

\begin{tabular}{|c|c|c|}
\hline Sample No. & Mass $\mathbf{~} \mathbf{1 0}^{-\mathbf{3}} \mathbf{( k g )}$ & Thickness $\mathbf{x} \mathbf{1 0}^{-3} \mathbf{( m )}$ \\
\hline 1 & 2.7 & 0.61 \\
\hline 2 & 3.03 & 0.58 \\
\hline 3 & 2.61 & 0.6 \\
\hline 4 & 1.78 & 0.24 \\
\hline 5 & 2.15 & 0.28 \\
\hline 6 & 4.77 & 0.25 \\
\hline
\end{tabular}

Table 2 : 100\% cotton knitted fabrics (single Jersey).

\begin{tabular}{|c|c|c|}
\hline Sample. No & Mass $\mathbf{~} \mathbf{1 0}^{-\mathbf{3}} \mathbf{( k g )}$ & Thickness $\mathbf{~} \mathbf{1 0}^{-\mathbf{3}} \mathbf{( m )}$ \\
\hline 1 & 3.74 & 0.5 \\
\hline 2 & 3.49 & 0.48 \\
\hline 3 & 4.09 & 0.48 \\
\hline 4 & 3.71 & 0.47 \\
\hline 5 & 3.76 & 0.53 \\
\hline 6 & 3.42 & 0.52 \\
\hline 7 & 3.43 & 0.51 \\
\hline 8 & 3.44 & 0.51 \\
\hline 9 & 3.45 & 0.52 \\
\hline 10 & 2.67 & 0.42 \\
\hline 11 & 2.39 & 0.41 \\
\hline 12 & 3.49 & 0.43 \\
\hline 13 & 3.5 & 0.49 \\
\hline 14 & 3.34 & 0.52 \\
\hline 15 & 2.1 & 0.41 \\
\hline 16 & 2.55 & 0.41 \\
\hline 17 & 2.69 & 0.49 \\
\hline
\end{tabular}

\section{Formulae:}
a. Heat Flow
b. $\quad \mathrm{Q}=\mathrm{SHC} \times(\mathrm{T} 1-\mathrm{T} 2) \times \mathrm{m}$

c. Thermal conductivity factor

d. $\quad \lambda=\mathrm{QL} / \mathrm{At}(\mathrm{T} 1-\mathrm{T} 2)$

e. Heat transfer Coefficient

f. $\quad \mathrm{K}=\mathrm{Q} /$ At $(\mathrm{T} 1-\mathrm{T} 2)$

g. Thermal Transmittance

i. $\quad \mathrm{U}=\mathrm{K} / \mathrm{L}$

h. Thermal Resistance

a. $\quad \mathrm{R}_{\mathrm{th}}=\mathrm{L} / \mathrm{K}$

Where,

SHC = Specific Heat Capacity of Cotton $(1162 \mathrm{~J} / \mathrm{Kg} \mathrm{C})$

$\mathrm{T} 1-\mathrm{T} 2=$ Temperature difference, in ${ }^{\circ} \mathrm{C}$

$\mathrm{m}=$ Mass of the fabric, in $\mathrm{Kg}$

$\mathrm{L}=$ Thickness of the fabric, in $\mathrm{m}$

$\mathrm{A}=$ Area of the fabric used $\left(0.016 \mathrm{~m}^{2}\right)$

$\mathrm{t}=$ Time of testing (3600s)

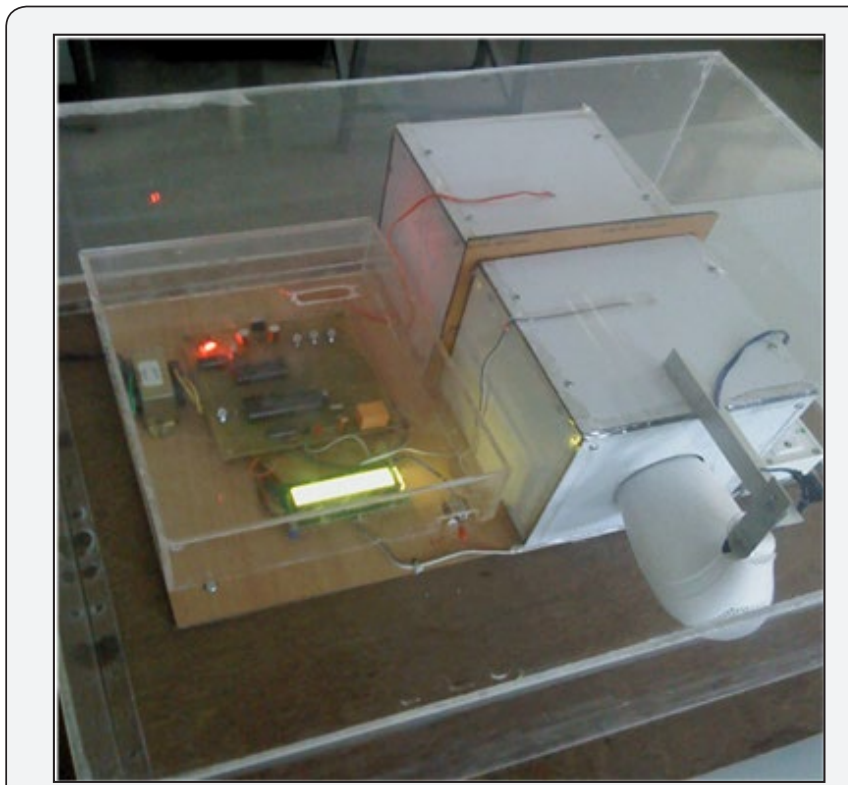

Figure 1: Instrument -Temperature Difference Tester.

Table 3: Woven fabric - thermal properties values.

\begin{tabular}{|c|c|c|c|c|c|c|c|c|}
\hline S. No. & Weave & $\begin{array}{c}\mathrm{L} \\
\times 10^{-3}(\mathrm{~m})\end{array}$ & $\begin{array}{c}\mathrm{m} \\
\times 10^{-3}(\mathrm{~kg})\end{array}$ & $\begin{array}{c}\text { (T1-T2) } \\
\text { (K) }\end{array}$ & $\begin{array}{c}Q \\
\times 10^{-3} \\
(\mathrm{~J}) \\
\end{array}$ & $\begin{array}{c}\lambda \\
\times 10^{-3} \\
\left(\mathrm{~W} \cdot \mathbf{m}^{-1} \mathbf{k}^{-1}\right)\end{array}$ & $\begin{array}{c}\text { Rth } \\
\left(\mathrm{m}^{2} \mathrm{~K} \cdot \mathbf{W}^{-1}\right)\end{array}$ & $\begin{array}{c}\mathbf{U} \\
\left(\mathbf{W} \cdot \mathbf{m}^{-2} \mathbf{k}^{-1}\right)\end{array}$ \\
\hline 1 & Plain & 0.24 & 1.78 & 3 & 9098.6 & 0.0125 & 0.00459 & 218.03 \\
\hline 2 & Plain & 0.28 & 2.15 & 3 & 7494.9 & 0.01207 & 0.00651 & 153.634 \\
\hline 3 & Plain & 0.58 & 3.03 & 3 & 10562.58 & 0.0352 & 0.0096 & 104.73 \\
\hline 4 & Plain & 0.6 & 2.61 & 2 & 6065.64 & 0.0241 & 0.0088 & 113.75 \\
\hline 5 & Plain & 0.61 & 2.7 & 3 & 9412.2 & 0.033019 & 0.01129 & 88.74 \\
\hline
\end{tabular}


Table 4: Knitted fabric - thermal properties values.r

\begin{tabular}{|c|c|c|c|c|c|c|c|c|}
\hline S. No. & Structure & $\begin{array}{c}\mathrm{L} \\
\times 10^{-3}(\mathrm{~m})\end{array}$ & $\begin{array}{c}\mathrm{m} \\
\times 10^{-3}(\mathrm{~kg})\end{array}$ & $\begin{array}{c}\text { (T1-T2) } \\
\text { (K) }\end{array}$ & $\begin{array}{c}Q \\
\times 10^{-3} \\
(J)\end{array}$ & $\begin{array}{c}\lambda \\
\times 10^{-3} \\
\left(W \cdot \mathbf{m}^{-1} \mathbf{k}^{-1}\right)\end{array}$ & $\begin{array}{c}\text { Rth } \\
\left(\mathrm{m}^{2} \mathrm{~K} \cdot \mathrm{W}^{-1}\right)\end{array}$ & $\begin{array}{c}U \\
\left(W \cdot m^{-2} k^{-1}\right)\end{array}$ \\
\hline 1 & Single Jersey & 0.41 & 2.39 & 2 & 554.36 & 0.01965 & 0.00438 & 116.81 \\
\hline 2 & Single Jersey & 0.41 & 2.1 & 2 & 4880.4 & 0.0173 & 0.00973 & 102.68 \\
\hline 3 & Single Jersey & 0.41 & 2.55 & 2 & 5926.2 & 0.021 & 0.00802 & 124.69 \\
\hline 4 & Single Jersey & 0.42 & 2.67 & 2 & 6205.08 & 0.0225 & 0.0079 & 127.44 \\
\hline 5 & Single Jersey & 0.43 & 3.49 & 2 & 8110.76 & 0.0301 & 0.00618 & 161.86 \\
\hline 6 & Single Jersey & 0.47 & 3.71 & 3 & 12933.06 & 0.0349 & 0.00631 & 158.25 \\
\hline 7 & Single Jersey & 0.48 & 3.49 & 3 & 12166.14 & 0.03359 & 0.00686 & 145.767 \\
\hline 8 & Single Jersey & 0.48 & 4.09 & 3 & 14257.74 & 0.0394 & 0.0059 & 170.82 \\
\hline 9 & Single Jersey & 0.49 & 3.5 & 3 & 12201 & 0.0344 & 0.00698 & 143.27 \\
\hline 10 & Single Jersey & 0.49 & 2.69 & 3 & 9377.34 & 0.02642 & 0.0091 & 110.06 \\
\hline 11 & Single Jersey & 0.5 & 3.74 & 3 & 13037.64 & 0.0749 & 0.0067 & 149.954 \\
\hline 12 & Single Jersey & 0.51 & 3.43 & 2 & 7971.32 & 0.0234 & 0.0111 & 89.88 \\
\hline 13 & Single Jersey & 0.51 & 3.44 & 3 & 11991.84 & 0.0351 & 0.0074 & 135.23 \\
\hline 14 & Single Jersey & 0.52 & 3.42 & 2 & 7948.08 & 0.0237 & 0.0114 & 87.904 \\
\hline 15 & Single Jersey & 0.52 & 3.45 & 3 & 12026.7 & 0.03597 & 0.0075 & 133.01 \\
\hline 16 & Single Jersey & 0.52 & 3.34 & 3 & 11643.24 & 0.03482 & 0.0078 & 128.772 \\
\hline 17 & Single Jersey & 0.53 & 3.76 & 3 & 13107.36 & 0.0395 & 0.00703 & 142.23 \\
\hline
\end{tabular}

\section{Results and Discussion}

\section{Woven fabric}

\section{With respect to thickness}

The above is the graph (Figure 2) between thermal transmittance and fabric thickness of $100 \%$ cotton of woven fabric (plain weave). As the thickness (L) of the fabric increases, the thermal transmittance $(U)$ value of the fabric decreases.

\section{Thermal Transmittance, $\mathrm{U}\left(\mathrm{W} \cdot \mathrm{m}^{-2} \mathrm{k}^{-1}\right)$}

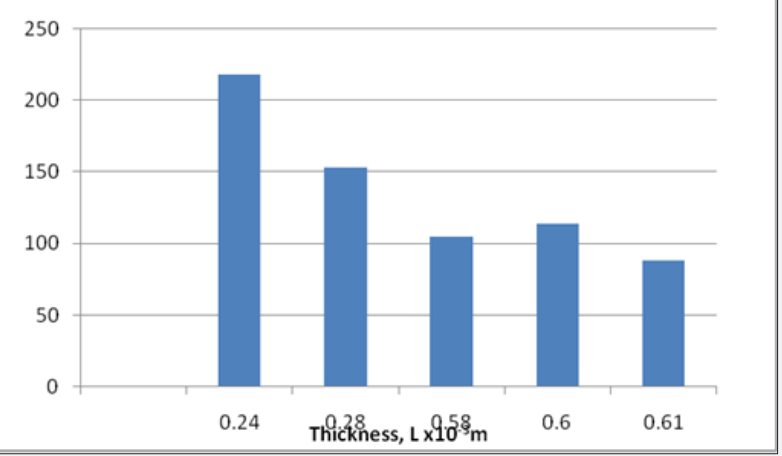

Figure 2 : Instrument -Temperature Difference Tester.

The above is the graph (Figure 3) between thermal resistance and fabric thickness of $100 \%$ cotton of woven fabric (plain weave). As the thickness (L) of the fabric increases, the thermal resistance (Rth) value of the fabric decreases.

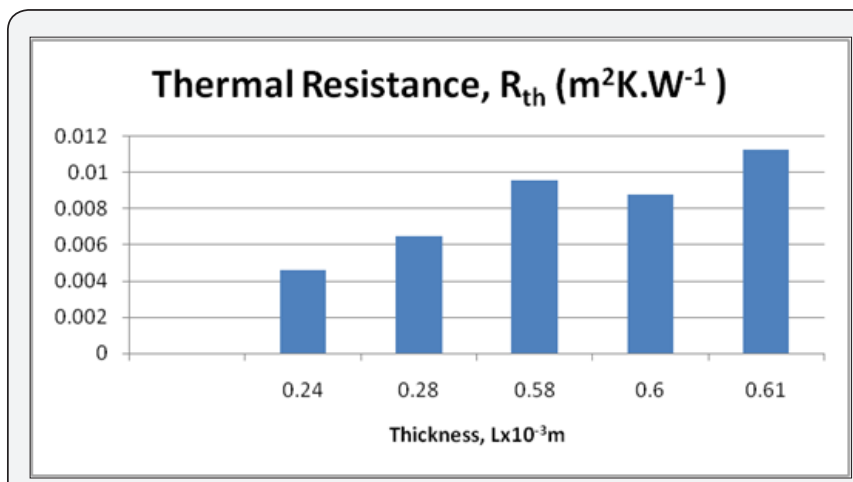

Figure 3 : Woven- Thermal Resistance vs. Thickness.

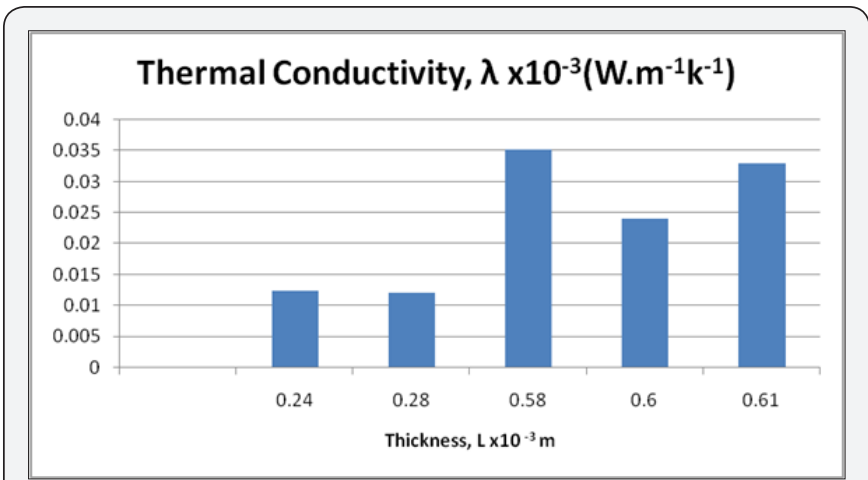

Figure 4 : Woven- Thermal Conductivity vs. Thickness. 
The above is the graph between (Figure 4) thermal conductivity and fabric thickness of $100 \%$ cotton of woven fabric (plain weave). As the thickness (L) of the fabric increases, the thermal conductivity $(\lambda)$ value of the fabric increases [15].

\section{With respect to mass}

The above is the graph (Figure 5) between thermal conductivity and fabric mass of $100 \%$ cotton of woven fabric (plain weave). As the mass (m) of the fabric increases, the thermal conductivity $(\lambda)$ value of the fabric increases.

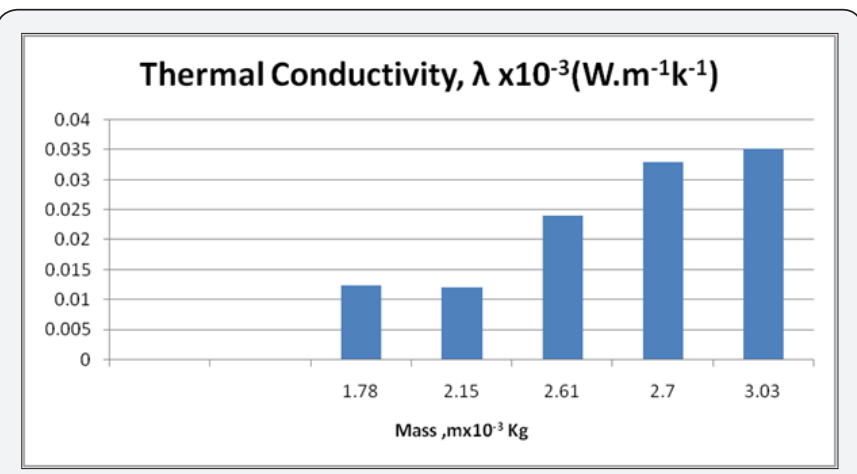

Figure 5 : Woven- Thermal Conductivity vs. Mass.

The above is the graph (Figure 6) between thermal conductivity and fabric mass ( 5 "x 5 ") of $100 \%$ cotton of woven fabric (plain weave). As the mass ( $m$ ) of the fabric increases, the thermal resistance $\left(R_{t h}\right)$ value of the fabric increases.

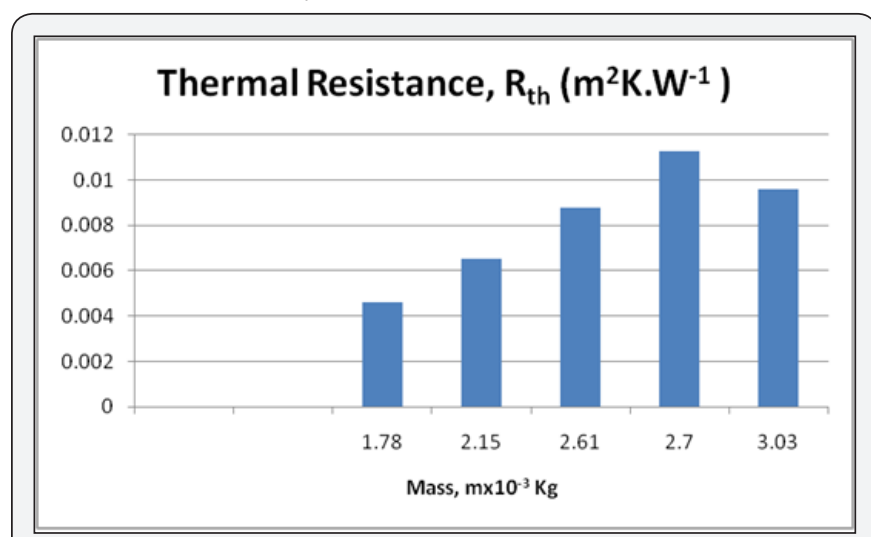

Figure 6 : Woven- Thermal Resistance vs. Mass.

The above is the graph (Figure 7) between thermal transmittance and fabric mass ( 5 "x 5 ") of $100 \%$ cotton of woven fabric (plain weave). As the mass ( $\mathrm{m}$ ) of the fabric increases, the thermal transmittance $(U)$ value of the fabric decreases.

\section{Knitted fabrics}

\section{With respect to thickness}

The above is the graph (Figure 8) between thermal resistance and fabric thickness of $100 \%$ cotton of knitted fabric (single jersey). As the thickness of the fabric increases, the thermal resistance $\left(R_{t h}\right)$ value of the fabric increases [16].

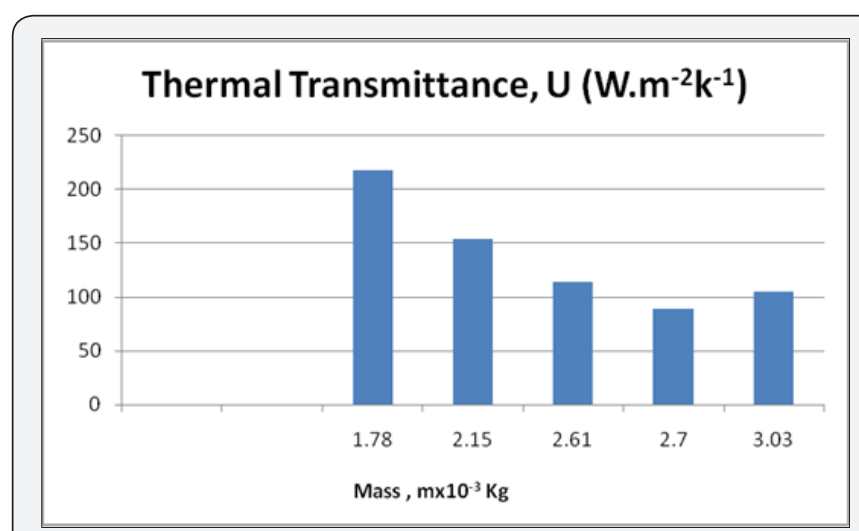

Figure 7 : Woven- Thermal Transmittance vs. Mass.

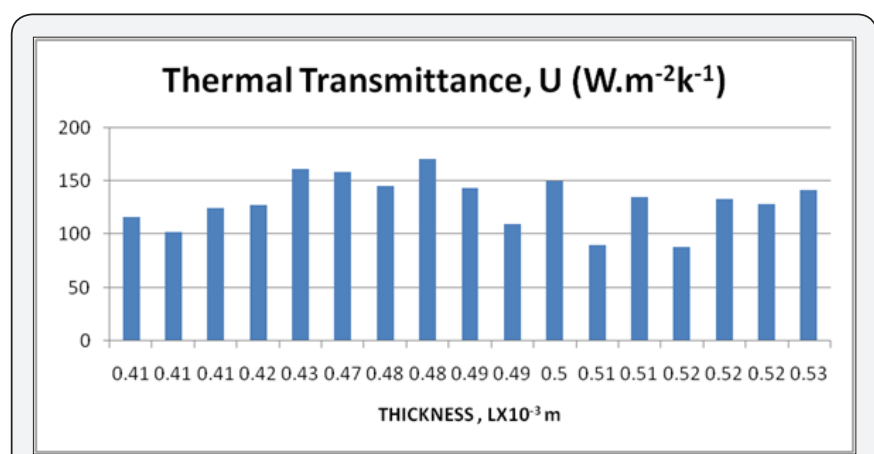

Figure 8 : Knitted- Thermal transmittance vs. Thickness.

The above is the graph (Figure 9) between thermal resistance and fabric thickness of $100 \%$ cotton of knitted fabric (single jersey). As the thickness of the fabric increases, the thermal resistance $\left(R_{t h}\right)$ value of the fabric increases. The unevenness is due to the variation in the cover factor [17-19].

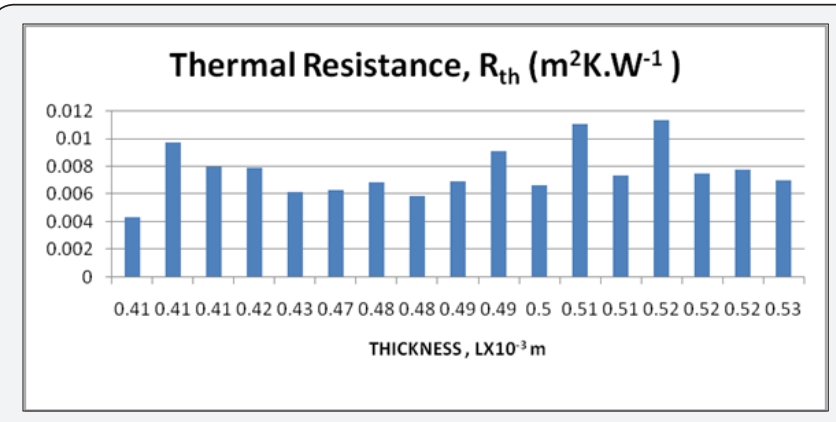

Figure 9 : Knitted- Thermal Resistance vs. Thickness.

The above is the graph (Figure 10) between thermal resistance and fabric thickness of $100 \%$ cotton of knitted fabric (single jersey). As the thickness of the fabric increases, the thermal Conductivity $(\lambda)$ value of the fabric increases.The unevenness is due to the variation in the cover factor.

\section{With respect to mass}

The above is the graph (Figure 11) between thermal resistance and fabric Mass of $100 \%$ cotton of knitted fabric (single jersey). As the thickness of the fabric increases, the thermal Resistance 
Rth value of the fabric increases. The unevenness is due to the variation in the cover factor.

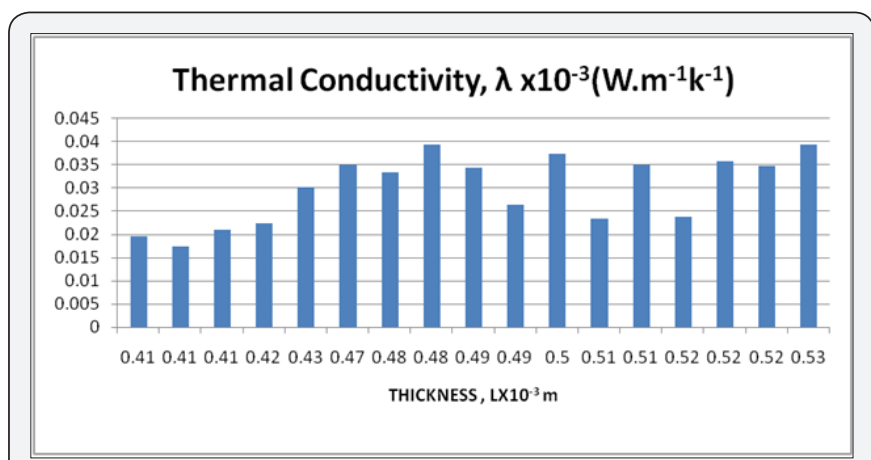

Figure 10 : Knitted- Thermal conductivity vs. Thickness.

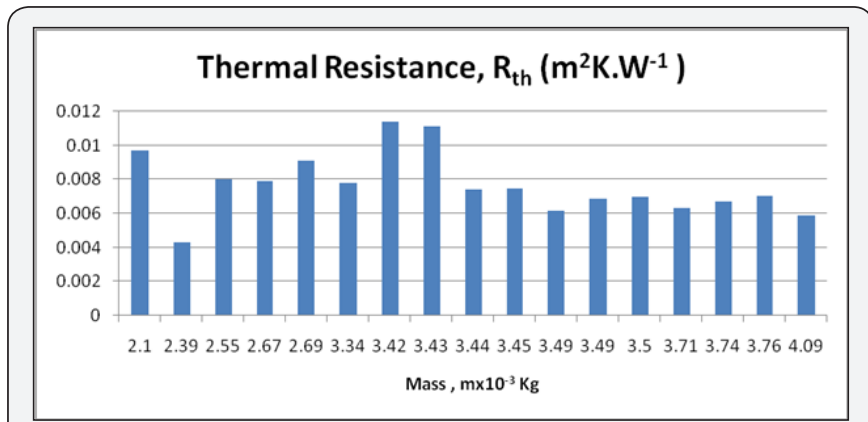

Figure 11 : Knitted- Thermal Resistance vs. Mass.

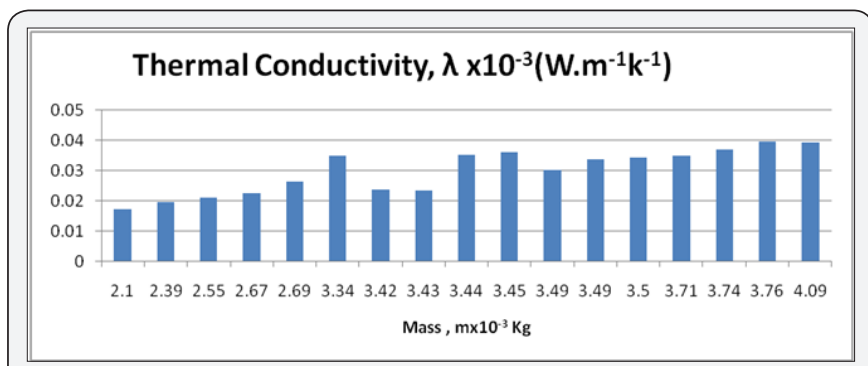

Figure 12 : Knitted- Thermal Conductivity vs. Mass.

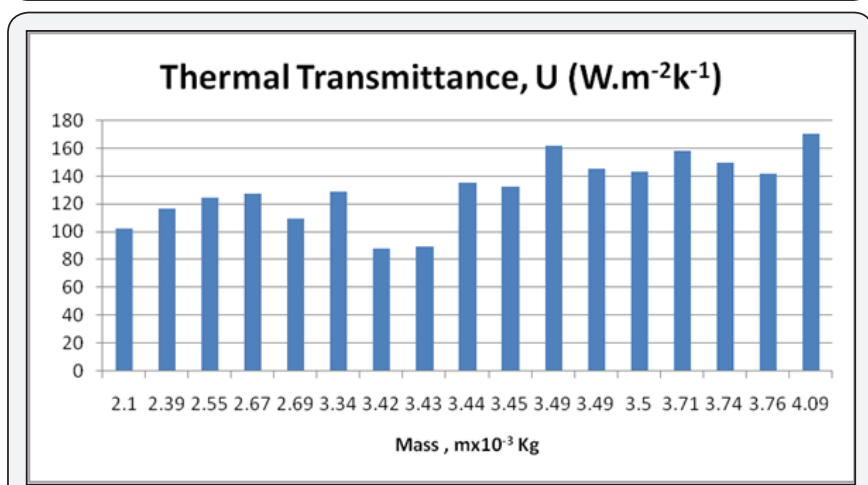

Figure 13 : Knitted- Thermal conductivity vs. Thickness.

The above is the graph (Figure 12) between thermal resistance and fabric Mass of $100 \%$ cotton of knitted fabric (single jersey). As the thickness of the fabric increases, the Thermal conductivity $(\lambda)$ value of the fabric increases.The unevenness is due to the variation in the cover factor.
The above is the graph (Figure 13) between thermal resistance and fabric Mass of $100 \%$ cotton of knitted fabric (single jersey). As the thickness of the fabric increases, the thermal Transmittance $U$ value of the fabric increases. The unevenness is due to the variation in the cover factor [20-22].

\section{Conclusion}

The thermal properties such as thermal transmittance, thermal resistance and thermal conductivity of textile fabrics varies with respect to the factors like fiber type, fabric structure, type of the weave ,fabric thickness, cover factor, texture of the fiber, weight of the fabric. The factors observed for this project are fiber type, fabric structure, fabric thickness and weight of the fabric. As far as our instrument in concerned, from the observations, we can conclude that for the woven fabrics as the thickness increases, the thermal transmittance decreases and the thermal resistance increases, similarly as the mass of the fabric increases the thermal transmittance decreases and the thermal resistance increases. Also for the knitted fabrics, as the thickness increases, the thermal transmittance decreases and the thermal resistance increases, similarly as the mass of the fabric increases the thermal transmittance decreases and the thermal resistance increases. All the factors of the fabric are interrelated in determining the thermal properties of the fabric. One particular factor with relevance to the other only will give the final behavior of the fabric towards thermal exposure. Therefore the thermal transmittance value varies with respect to thickness, tightness factor and mass of fabric.

\section{References}

1. Jebastin Rajwin A, Prakash C (2017) Effect of Air Plasma Treatment on Thermal Comfort Properties of Woven Fabric. International Journal of Thermophysics 38: 166.

2. Sowmya R, Vasugi RN, Subramaniam V, Prakash C (2017) Investigation of relationship between blend ratio and yarn twist on yarn properties of bamboo, cotton, polyester and its blends. Journal of Natural Fibers 14(2): 228-238.

3. Karthikeyan G, Nalankilli G, Shanmugasundram OL, Prakash C (2017) Moisture Management Properties of Bamboo Viscose/Tencel Single Jersey Knitted Fabrics. Journal of Natural Fibers 14(1): 143-152.

4. Kumar V, Sampath VR, Prakash C (2016) Investigation of Stretch on Air Permeability of Knitted Fabrics Part II: Effect of Fabric Structure. The Journal of The Textile Institute 107(10): 1213-1222.

5. Karthikeyan G, Nalankilli G, Shanmugasundram OL, Prakash C (2016) Thermal comfort properties of bamboo tencel knitted fabrics. International Journal of Clothing Science and Technology 28(4): 420428.

6. Prakash C, Ramakrishnan G, Mani K, Keerthana S (2015) An Investigation of the Relationship between Blend ratio, linear density and loop length on geometrical and air permeability properties of bamboo cotton knitted fabrics. International Journal of Fashion Design, Technology and Education 8(3): 228-234.

7. Ramakrishnan G, Umapathy P, Prakash C (2015) Comfort properties of bamboo/cotton blended knitted fabrics produced from rotor spun yarns. The Journal of The Textile Institute 106(12): 1371-1376.

8. Raja D, Prakash C, Gunasekaran G, Koushik CV (2015) A study on thermal properties of single-jersey knitted fabrics produced from ring 
and compact folded yarns. The Journal of The Textile Institute 106(4) 359-365.

9. Raja D, Prakash C, Ramakrishnan G, Koushik CV (2014) Influence of blend ratio and linear density on liquid spreading characteristics of bamboo/cotton-blended yarn knitted fabrics measured by liquid spread tester. The Journal of The Textile Institute 105(8): 842-849.

10. Prakash C, Ramakrishnan G, Koushik CV (2013) Effect of blend proportion on moisture management characteristics of bamboo/ cotton knitted fabrics. Journal of The Textile Institute 104(12): 1320 1326.

11. Prakash C, Ramakrishnan G, Chinnadurai S, Vignesh S, Senthilkumar M (2013) Effect of Plasma Treatment on Air and Water-Vapor Permeability of Bamboo Knitted Fabric. International Journal of Thermophysics 34(11): 2173-2182.

12. Prakash C, Ramakrishnan G (2014) Study of Thermal Properties of Bamboo/Cotton Blended Single Jersey Knitted Fabrics. Arabian Journal for Science and Engineering 39(3): 2289-2294

13. Prakash C, Ramakrishnan G (2013) Effect of blend proportion on thermal behaviour of bamboo knitted fabrics. The Journal of The Textile Institute 104(9): 907-913

14. Prakash C, Ramakrishnan G, Koushik CV (2013) A Study of the therma properties of bamboo knitted fabrics. Journal of Thermal Analysis and Calorimetry 111 (1): 101-105.

15. Prakash C, Ramakrishnan G (2013) Effect of blend ratio, loop length, and yarn linear density on thermal comfort properties of single jersey knitted fabrics. International Journal of Thermophysics 34(1): 113121.
16. Rajalakshmi M, Koushik CV, Prakash C (2012) Effect of Cotton/ Micro polyester Blends on Physical Properties of Ring Spun Yarn. International Journal of Current Research 4(12): 040-043.

17. Prakash C, Ramakrishnan G, Koushik CV (2012) A study of the thermal properties of single jersey fabrics of cotton, bamboo and cotton/ bamboo blended-yarn vis-a-vis bamboo fibre presence and yarn count. Journal of Thermal Analysis and Calorimetry 110(3): 1173-1177.

18. Prakash C, Ramakrishnan G, Koushik CV (2011) The effect of loop length and yarn linear density on the thermal Properties of bamboo knitted fabric. AUTEX Research Journal 11(4): 102-105.

19. Prakash C, Ramakrishnan G, Koushik CV (2011) Effect of Blend Ratio on the Quality Characteristics of Bamboo/Cotton Blended Ring Spun Yarn. FIBRES \& TEXTILES in Eastern Europe 19(6) (89): 38-40.

20. Yuvarani M, Ramesh Chandra N, Prakash C, Koushik CV (2010) Investigation of wetting and wicking behaviour of trilogical Treated cotton fabric by vertical wicking principle. International journal of current research 9: 005-009.

21. Prakash C, Ramakrishnan G, Koushik CV (2012) Study of Thermal Comfort Properties of Cotton/Regenerated Bamboo Knitted Fabrics. African Journal of Basic \& Applied Sciences 4(2): 60-66.

22. Prakash C, Ramakrishnan G (2012) Effect of blend ration on quality Characteristics of bamboo/cotton blended ring Spun yarn. Daffodil International University Journal of Science and Technology 7(1): 3437.

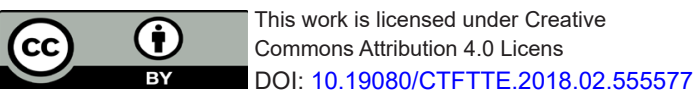

Swift Peer Review

- Reprints availability

- E-prints Service

- Manuscript Podcast for convenient understanding

- Global attainment for your research

- Manuscript accessibility in different formats

( Pdf, E-pub, Full Text, Audio)

- Unceasing customer service

Track the below URL for one-step submission https://juniperpublishers.com/online-submission.php 